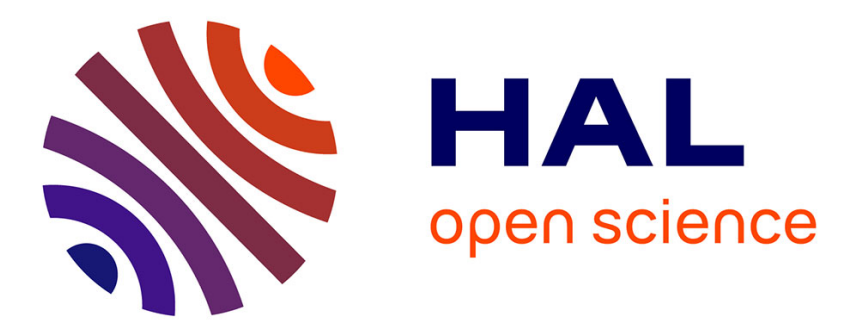

\title{
SARAL/AltiKa Wet Tropospheric Correction: In-Flight Calibration, Retrieval Strategies and Performances
}

\author{
Bruno Picard, Marie-Laure Frery, Estelle Obligis, Laurence Eymard, N. \\ Steunou, Nicolas Picot
}

\section{To cite this version:}

Bruno Picard, Marie-Laure Frery, Estelle Obligis, Laurence Eymard, N. Steunou, et al.. SARAL/AltiKa Wet Tropospheric Correction: In-Flight Calibration, Retrieval Strategies and Performances. Marine Geodesy, 2015, The SARAL/AltiKa Satellite Altimetry Mission, 38 (Supplement 1), pp.277-296. 10.1080/01490419.2015.1040903 . hal-01233761

\section{HAL Id: hal-01233761 https://hal.science/hal-01233761}

Submitted on 7 Apr 2020

HAL is a multi-disciplinary open access archive for the deposit and dissemination of scientific research documents, whether they are published or not. The documents may come from teaching and research institutions in France or abroad, or from public or private research centers.
L'archive ouverte pluridisciplinaire HAL, est destinée au dépôt et à la diffusion de documents scientifiques de niveau recherche, publiés ou non, émanant des établissements d'enseignement et de recherche français ou étrangers, des laboratoires publics ou privés. 


\title{
SARAL/AltiKa Wet Tropospheric Correction: In-Flight Calibration, Retrieval Strategies and Performances
}

\author{
B. PICARD,${ }^{1}$ M.-L. FRERY,${ }^{1}$ E. OBLIGIS,${ }^{1}$ L. EYMARD,${ }^{2}$ \\ N. STEUNOU, ${ }^{3}$ AND N. PICOT $^{3}$ \\ ${ }^{1}$ Collecte Localisation Satellites (CLS), Space Oceanography Division, \\ Ramonville St-Agne, France \\ ${ }^{2}$ Laboratoire d'Océanographie et du Climat: Expérimentations et Approches \\ Numériques (LOCEAN), Centre National de la Recherche Scientifique (CNRS), \\ Paris, France \\ ${ }^{3}$ Centre National d'Etudes Spatiales (CNES), Toulouse, France
}

\begin{abstract}
The SARAL/AltiKa mission is a complement of the Jason altimeter series. A twochannels $(23.8 \mathrm{GHz}$ and $37 \mathrm{GHz})$ microwave radiometer $(M W R)$ is combined to the altimeter in order to correct the altimeter range for the excess path delay (referred as WTC for wet tropospheric correction. First, the in-flight calibration of AltiKa MWR is assessed from a systematic comparison to other radiometers using a complete set of metrics (comparison to simulations and over geophysical targets). Then the "mixed" empirical approach successfully used for Envisat shows nonoptimal performances for the WTC retrieval. In order to find the potential sources of issues, this method is compared to a purely empirical relationship established between measured brightness temperatures $(T B)$ and altimeter backscattering coefficient $\left(\sigma_{0}\right)$ on one hand and modeled WTC on the other hand. Various retrieval configurations for both AltiKa MWR and advanced microwave radiometer (AMR) on Jason-2, are for the first time systematically compared with respect to their performances against the variance of sea surface height differences at crossovers. Finally, the issues on the "mixed" approach are attributed to the differences between simulated and measured $\sigma_{0}$ at Ka-band. Now, a configuration of the empirical approach proved to have performances closed to what is initially expected with the "mixed" approach.
\end{abstract}

Keywords Altimetry, data quality, microwave radiometry, wet tropospheric correction

\section{Introduction}

The SARAL/AltiKa mission is a complement of the Jason altimeter series. The use of a $\mathrm{Ka}$ band altimeter results in better performances in terms of spatial resolution and accuracy. A two-channel microwave radiometer $(23.8 \mathrm{GHz}$ and $37 \mathrm{GHz})$ is combined to the altimeter backscattering coefficient $\left(\sigma_{0}\right)$ in order to correct the altimeter range for the excess path delay (noted WTC for wet tropospheric correction) resulting from the

Address correspondence to Bruno Picard, Collecte Localisation Satellites (CLS), Space Oceanography Division, 8-10 Rue Hermès, 31520 Ramonville St-Agne, France. E-mail: bruno. picard@cls.fr 
presence of water vapor in the troposphere. Brightness temperatures (TB) are also used for the estimation of the atmospheric attenuation of the backscattering coefficient, which is significant in the Ka band. The microwave radiometer on SARAL/AltiKa mission (ALMWR) performs measurements of brightness temperatures in both bands at the location of the altimeter footprint. First results at instrumental level exhibit its very good thermal stability, its very fine sensitivity and its sharp spatial resolution, making of AltiKa radiometer one of the best in-flight radiometers (Steunou et al. 2015).

The $23.8 \mathrm{GHz}$ channel, chosen near the water vapor absorption line at $22.235 \mathrm{GHz}$, is the most correlated to the WTC and the $37 \mathrm{GHz}$ channel, while also well-correlated to WTC, allows accounting for the cloud liquid water. Thus, the quality of the brightness temperatures is crucial for the quality of the radiometer geophysical parameters retrieval. Section 2 is dedicated to the validation of the TB of both channels using usual metrics: comparison to simulated TB over ocean, vicarious calibration of coldest TB over ocean and hottest TB over land, and systematic comparison to Jason-2 Advanced Microwave Radiometer (AMR) and the Advanced Microwave Sounding Unit (AMSU-A) on Metop02.

In Section 3, we present two empirical approaches for the retrieval of AltiKa radiometer L2 products: a classical "mixed" approach successfully used in the past for ERS-1, ERS-2, and Envisat MWR and an alternative method, purely empirical. The linear transfer function between the simulated inputs and the measurements, a critical step for the "mixed" approach, is described as well. Then, the difficulty of the comparison between measured and simulated backscattering coefficients specific to Ka-band is discussed and finally, the first elements for the validation of the "mixed" approach WTC are given.

For the first time, the corresponding performances of various retrieval configurations, varying the number and the nature of the inputs, are evaluated in Section 4 against improvement of the SSH variance at crossovers (w.r.t. ECMWF (European Centre for Medium range Weather Forecasting) WTC) and compared to Jason-2 AMR.

Finally, Section 5 is dedicated to the conclusions.

\section{SARAL/AltiKa Radiometer In-flight Calibration}

The on-ground calibration of the receiver consists on the calibration and characterization of each element of the radiometric model. Usually the reflector cannot be included during the system characterization and the antenna pattern is measured separately. Moreover, it is very difficult to estimate the brightness temperature aiming the side lobe of the antenna pattern or the albedo of the surface seen by spill-over effect. This means that the onground characterization is not fully representative of the on-flight behavior and that the calibration of the receiver has to be assessed after launch.

The in-flight calibration is made difficult in microwave radiometry by the lack of reference natural target well-known or homogeneous enough. It is also important to assess the calibration in the whole range of brightness temperatures seen over ocean. Each inflight instrument has its own calibration strategy. For AltiKa microwave radiometer (AL-MWR), the methodology is based on several analyses:

- Comparison over ocean using the vicarious cold calibration method

- Comparison to other instruments (AMR on Jason-2, AMSU-A on Metop02) over continental areas such as Amazon

- Comparing measured brightness temperatures with simulated ones over ocean, using collocated profiles from ECMWF model analyses. 
In the following for AMR Jason-2 radiometer, the brightness temperatures at $23.8 \mathrm{GHz}$ and $34 \mathrm{GHz}$ and the wet tropospheric correction (WTC) are extracted from Jason-2 Level 2 GDR-D (Geophysical Data Records) product version, available via AVISO FTP (Archivage, Validation et Interprétation des données des Satellites Océanographiques ftp://avisoftp.cnes.fr/AVISO/pub/jason-2/gdr_d/) or PODAAC FTP (Physical Oceanography Distributed Active Archive Center, ftp://data.nodc.noaa.gov/ pub/data.nodc/jason2/gdr/gdr/). AMSU-A along track brightness temperatures are extracted from L1B data available at ICARE archive center (Interactions Clouds Aerosols Radiations Etc http://www.icare.univ-lille1.fr/). AMSU-A is an across-track scanning radiometer and no nadir measurement is available. Nadir brightness temperatures at $23.8 \mathrm{GHz}$ and $31.4 \mathrm{GHz}$ are built from the linear interpolation of the two closest samples on each side of the nadir.

\subsection{Coldest Brightness Temperature over Ocean}

Ruf (2000) demonstrates how a statistical selection of the coldest TB over ocean allows detecting and monitoring any potential drifts on brightness temperatures (Ruf 2000). It is also commonly used for long-term monitoring or cross-calibration (Ruf 2002; Scharroo et al. 2004; Eymard et al. 2005; Kroodsma et al. 2012).

In the following, Eymard method derived from Ruf's is used (Eymard et al. 2005). Over each SARAL/AltiKa cycle, cold brightness temperatures are selected by keeping data below Ruf's threshold $+10 \mathrm{~K}$ : this criterion is applied to all channels simultaneously when Ruf applied his selection separately. Then, the mean and standard deviation of the selected TB are computed. Finally, the coldest TB value for a given cycle is computed by averaging the cold TB falling below the mean minus 1.5 times the standard deviation.

The results obtained for AL-MWR, AMR on Jason 2 and AMSU-A on Metop02 over the first 10 cycles of SARAL/AltiKa (March 2013 to March 2014) are shown in Figure 1 (top x-axis shows the Julian days since January 1st, 1950). For the $23.8 \mathrm{GHz}$ channel, the coldest brightness temperatures over ocean for AL-MWR and AMSU-A are very close to each other with less than $1 \mathrm{~K}$ of difference where AMR stands with $5 \mathrm{~K}$ lower than AMSU-A. This difference could be attributed to specific calibration strategy choices for AMR. The long-term calibration of AMR is insured by a method detailed in Brown (2013), based on ocean observations and observations over the Amazon forest, which main goal is to mitigate the known instrumental drift, when the calibration of AL-MWR TB is ensured by the on-ground calibration.
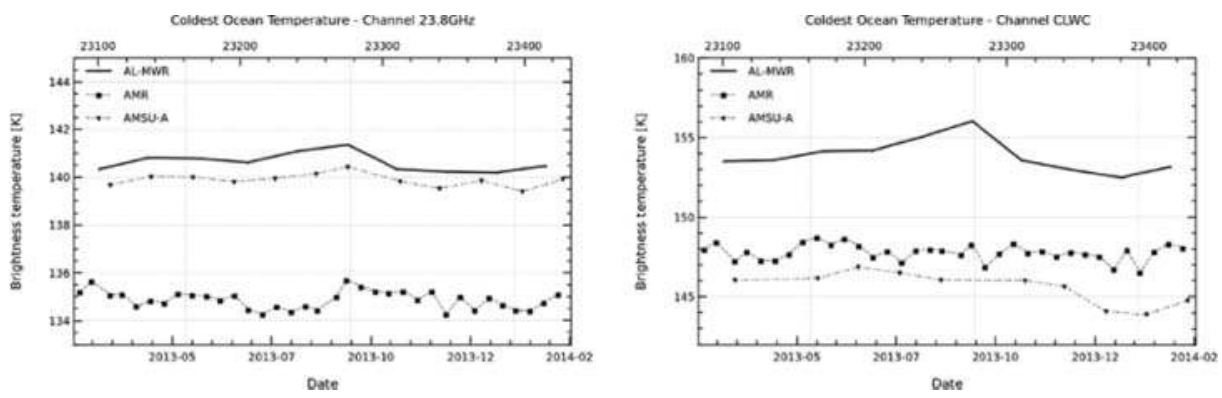

Figure 1. Times series of ocean coldest brightness temperatures at $23.8 \mathrm{GHz}$ (left) and CLWC channels (right) for AL-MWR (solid line), AMR (dashed line) and AMSU-A (dotted line). 
For the cloud liquid water content (CLWC) channel, at $37 \mathrm{GHz}$ for AL-MWR, $34 \mathrm{GHz}$ for AMR, and $31.4 \mathrm{GHz}$ for AMSU-A, the analysis is less straightforward as the three instruments have different frequencies. Moreover the brightness temperatures of this channel for AL-MWR were impacted by a saturation of the hot calibration counts until 22 October 2013 when an on-board database update fixed this issue (see Steunou et al. 2015). Corrective solutions are currently under investigation, but it is difficult at the moment to precisely give a starting date from which the saturation has a measurable impact on the TB, even if the impact is obvious on the hottest TB monitoring (see dedicated section below) from the beginning of August (AltiKa cycle 5). Then, the mean values of the coldest ocean brightness temperatures for the three instruments given by Table 1 is computed for the whole first 10 cycles, even for the $37 \mathrm{GHz}$ channel of AL-MWR. Now, the difference between AL-MWR $37 \mathrm{GHz}$ and AMR $34 \mathrm{GHz}$ is around $6 \mathrm{~K}$ before and after the saturation issue period which is in line with the theoretical value estimated by Brown between the channel $34 \mathrm{GHz}$ of JMR and the channel $37 \mathrm{GHz}$ of TMR $(-5.61 \mathrm{~K} \pm 0.23 \mathrm{~K})$ (Brown et al. 2004).

\subsection{Hottest Brightness Temperatures over Amazon Forest}

The Amazon forest was shown to be the closest of a natural blackbody for microwave radiometry, and it is commonly used to assess the calibration of microwave radiometers (Brown 2005; Eymard et al. 2005).

The same region as in Eymard et al. (2005) is selected (latitudes between $-5.5^{\circ}$ and $-4.5^{\circ}$ and longitudes between $+64.5^{\circ}$ West and $+67.0^{\circ}$ West) and, as recommended by the author, nightime hours measurements only are considered, the variation over seasons and the standard deviation being slightly lower than for daytime hours. For AltiKa, night passes occur at the end of the night just before sunrise (06:00 AM). For Metop02 night passes occur at the beginning of the night just after sunset (09:30 PM) so it is expected that the brightness temperatures for AMSU-A will be a little larger, as shown by the diurnal cycle observed over this area (Eymard et al. 2005). Jason-2 has on a non-sun-synchronous orbit but the brightness temperatures are quite stable during the night (see Eymard et al. 2005) so this allows extending the time span for the comparison: measurements between 00AM and 07AM are selected for AMR and the averaging is performed over 3 cycles (30 days) in order to achieve a consistent number of observations.

Figure 2 shows the results for AL-MWR, AMR, and AMSU-A for $23.8 \mathrm{GHz}$ channels on the left, and CLWC channels on the right (top x-axis shows the Julian days since 1 January 1950). Table 2 gives the mean of the nighttime Amazon Forest brightness temperatures over the first 10 cycles of AltiKa (March 2013 to March

Table 1

Mean values of ocean coldest brightness temperatures over the first 10 cycles of AltiKa for AL-MWR, AMR and AMSU-A

\begin{tabular}{lcc}
\hline \multicolumn{3}{c}{ Mean Ocean Coldest Brightness Temperature [K] } \\
\hline AL-MWR & $23.8 \mathrm{GHz}$ & CLWC \\
\hline AMR & 140.6 & 153.9 \\
AMSU-A & 134.9 & 147.8 \\
\hline
\end{tabular}



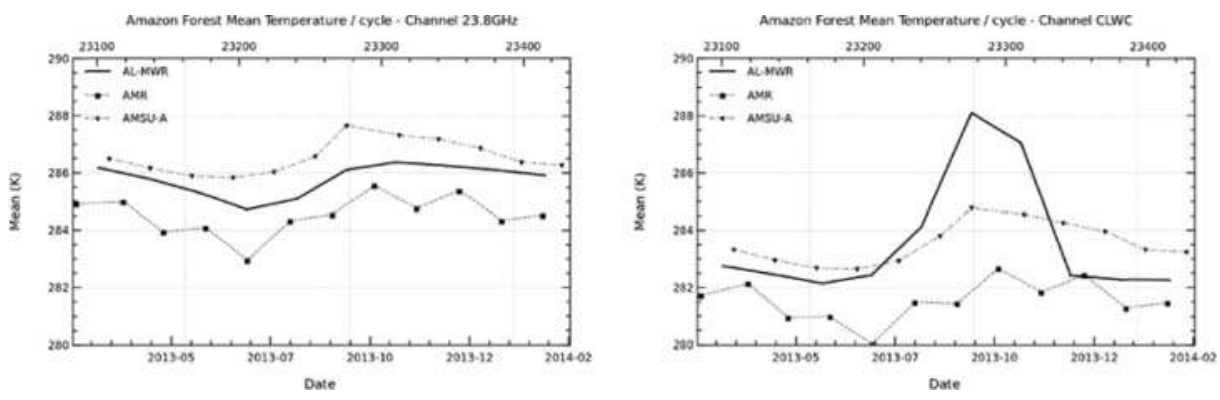

Figure 2. Times series of hottest brightness temperatures over Amazon forest at $23.8 \mathrm{GHz}$ (left) and CLWC channel (right) for AL-MWR (solid line), AMR (dashed line), and Metop-02 (dotted line).

2014). For the $23.8 \mathrm{GHz}$ channels, the results are very close for the three missions with differences of $+1.2 \mathrm{~K}$ between AL-MWR and AMR and $+2 \mathrm{~K}$ between AMSU-A and AMR. The seasonal cycle is potentially larger on AL-MWR than on the other two missions, with a difference of $2 \mathrm{~K}$ between AL-MWR and AMSU-A during spring and summer and less than $1 \mathrm{~K}$ during the end of autumn and winter, but long term conclusions cannot be drawn before a few years. For the CLWC channels, the saturation of the hot calibration counts is clearly seen with an expected greater impact for hot temperatures than for cold temperatures. For this channel, the mean values of AL-MWR TB are consistent with the measurements provided by the other two instruments.

\subsection{Comparison to Simulated Brightness Temperature over Open Ocean}

Profiles from the European Centre for Medium range Weather Forecasting (ECMWF) model analyses and a radiative transfer model were used to simulate brightness temperatures over ocean (see Section 3 for more details). Four global analyses per day (every six hours) for each day of SARAL/AltiKa first four cycles were processed (with an expected small impact of the saturation issue on the $37 \mathrm{GHZ}$ channel over this period), within a limited band of latitudes between $\pm 60^{\circ}$ to avoid sea ice. A space-time threshold of $\pm 50 \mathrm{~km}$ and \pm 30 minutes was applied as a collocation criterion between measurements and simulations. The comparison is performed over limited areas resulting from the combination of SARAL/AltiKa sun-synchronous orbit and the time collocation criterion, but the statistics are still representative of the global situation.

Table 2

Mean of Amazon Forest Brightness temperatures over the first 10 cycles of AL-MWR, AMR and AMSU-A

\begin{tabular}{lcc}
\hline \multicolumn{3}{c}{ Nighttime Amazon Forest Mean Brightness temperature [K] } \\
\hline AL-MWR & $23.8 \mathrm{GHz}$ & CLWC \\
AMR & 285.8 & 283.4 \\
AMSU-A & 284.6 & 281.7 \\
\hline
\end{tabular}


In order to improve the consistency of the comparison, outliers are filtered out by applying two additional selection criteria on the differences between simulations and measurements. Large differences may be explained by land contamination of the measured TB in the last $15 \mathrm{~km}$ from the coast (Valladeau et al. 2015) or by the difficulty of handling cloudy situations by numerical meteorological models, in terms of time, location, and intensity. Then, for a given channel, the differences between simulated and measured TB greater than $20 \mathrm{~K}$ are rejected, and differences between ECMWF integrated CLWC and CLWC estimated from measured TB larger than $10 \mathrm{~kg} / \mathrm{m}^{2}$ as well. An empirical log-linear relation is used to compute CLWC from measured TB (see Eymard et al. 1996).

Figure 3 presents scatterplots diagram built from these collocated and filtered data for both channels. Biases up to a few Kelvin $( \pm 5 \mathrm{~K})$ between measured and simulated TB have not impact on the actual performances of the radiometer and are even expected due to the limitation in the radiative transfer model, in the meteorological analyses and to the choices made for the on-ground calibration of the radiometer as well (Obligis et al. 2006). The standard deviation on the difference between measurements and simulations is mainly the signature of the temporal and spatial inconsistency between the analyses and the measured TB (the instrumental sensitivity being close to $+0.15 \mathrm{~K}$; see Steunou et al. 2015). Finally, the slope of the linear fit on the scatterplot should be close to +1.0 . Note that a larger standard deviation and a slope less closer the bisecting line is expected for the CLWC channel due to a remaining effect of clouds. The thresholds on acceptable biases, standard deviation and slopes are purely empirical and based on the experience accumulated with other instruments.

For the $23.8 \mathrm{GHz}$ channel, the mean bias between simulations and measurements is around $-3 \mathrm{~K}$ with a standard deviation of $2.8 \mathrm{~K}$, the slope of the linear fit is about $+1.03 \mathrm{~K} /$ $\mathrm{K}$. For the $37 \mathrm{GHz}$ channel, the mean bias is smaller around $+0.3 \mathrm{~K}$ with a standard deviation of $3 \mathrm{~K}$ and a slope of the linear fit of $+1.08 \mathrm{~K} / \mathrm{K}$. These results show the good agreement between the simulations and the measurements for both channels, in accordance with similar comparisons performed on ERS-2 and Envisat radiometers (see Obligis et al. 2006).
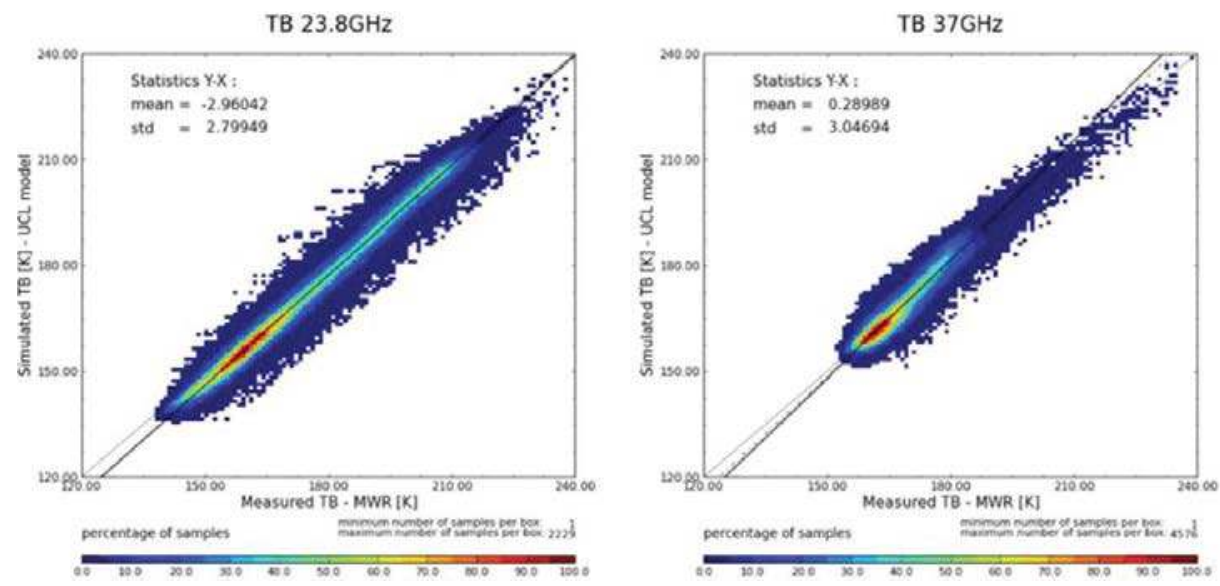

Figure 3. Scatterplots between simulated brightness temperatures and measurements at $23.8 \mathrm{GHz}$ (left) and $37 \mathrm{GHz}$ (right). The thin line is the bisecting line; the bold and the dashed lines respectively refer to a nonweighted linear regression and a weighted linear regression (taking into account the density in each bin). 


\subsection{Conclusion on SARAL/AltiKa Radiometer In-flight Calibration}

AL-MWR TB for both channels has been validated through the comparison to Jason-2/ AMR and Metop02/AMSU-A over geophysical targets, coldest ocean TB and hottest TB over the Amazon forest, and the comparison to simulated TB.

The observed biases are lower than $2 \mathrm{~K}$ for the $23.8 \mathrm{GHz}$ whatever the reference and the selection on the data, at the exception of a bias of $5 \mathrm{~K}$ compared to AMR $23.8 \mathrm{GHz}$ coldest TB over ocean. The same difference is nevertheless lower than $1 \mathrm{~K}$ comparing coldest TB of AL-MWR to AMSU-A; the large bias between AL-MWR and AMR could then be attributed to different calibration strategies.

The impact of the saturation of hot calibration counts on AL-MWR $37 \mathrm{GHz}$ channel is clearly seen on the vicarious calibration metrics with an expected larger impact on hottest TB than on coldest TB (see Steunou et al. 2015). The assessment of the $37 \mathrm{GHz}$ channel would not be straightforward even if the saturation was corrected, due to a combination of the different central frequencies used by the different radiometers, their different calibration strategies and the impact of clouds on comparison to simulated TB. But, even taking into account these limitations, the calibration of this channel seems acceptable.

In conclusion, and despite this notable event, the calibration of AL-MWR is completely consistent with the considered references.

\section{SARAL/AltiKa Radiometer Geophysical Parameters Retrieval Algorithms}

\subsection{The "Mixed" Approach}

3.1.1. Methodology. A "mixed" retrieval approach has been successfully applied on ERS-1 MWR, ERS-2 MWR, and Envisat MWR radiometers, the adjective "mixed" referring to the compromise between statistical and physical methods. Indeed, the physical part of this approach is included in a radiative transfer model used to simulate brightness temperatures from a large number of meteorological situations provided by numerical weather model analyses. The statistical part is included in the inversion process used to establish the relation between the inputs, the two AL-MWR brightness temperatures and the altimeter backscattering coefficient, and the expected outputs, the radiometer geophysical parameters: water vapor, atmospheric attenuation of $\sigma_{0}$, cloud liquid water content and the wet tropospheric correction (WTC). We will focus on this latter in the following. As for Envisat MWR, a neural network (NN) is used for AL-MWR to perform the regression.

Details of this method are described in Obligis et al. (2006): surface fields and profiles from the European Centre for Medium-Range Weather Forecasts (ECMWF) are used as inputs to the Université Catholique de Louvain (UCL) radiative transfer model (Guissard et al. 1987; Boukabara et al. 2002) to simulate TB and $\sigma_{0}$. The analyses at 12:00 UTC from the first day of each month are extracted on a $0.5^{\circ} \times 0.5^{\circ}$ global grid over the whole 2012 year. Only latitudes between $\pm 60^{\circ}$ are selected to avoid sea ice. The database consists of the simulated TB and $\sigma_{0}$ on one hand and the WTC computed directly from ECMWF humidity, temperature, and pressure profiles on the other hand. The learning database is built from a uniform random selection of $20 \%$ of the quadruplets, the $80 \%$ remaining representing the test database. 
The neural network architecture consists of one hidden layer with 8 neurons, the transfer function of which is hyperbolic tangent sigmoid. The output layer transfer function is linear. More details on the retrieval method are provided in Obligis et al. (2006).

The core of the "mixed" approach is threefold: the description of the surface (roughness, emissivity) and of the atmospheric (emission/absorption processes) properties by the radiative transfer model, the good representativity of all possible atmospheric situations by the meteorological model, and the consistency between the simulated brightness temperatures and the meteorological conditions.

Now, since the neural network is learned on a simulated dataset, optimal performances for the retrieval will be reached using the actual measurements provided by the radiometer and the altimeter only if a valid transfer function is found between the simulations and the measurements. The in-flight calibration of SARAL/AltiKa radiometer being assessed in the previous section, a linear relation should be sufficient to ensure the consistency between measurements and simulations.

3.1.2. The measured-to-simulated-brightness-temperatures transfer function. To estimate the linear relation between measured and simulated TB, a cumulative process has been implemented. At each iteration of the scheme, a day of collocated data is added to the dataset and a linear fit is performed. Then the fitting coefficients are monitored. When the dataset is statistically representative of all the possible atmospheric conditions, the values of the fitting coefficients should stabilize. We are therefore limited by the constant local time of SARAL/AltiKa passes and then a partial spatial coverage of the ocean around the four profiles of ECMWF analyses per day.

Figure 4 presents the monitoring of the fitting coefficients for both channels. It starts with strong oscillations at the beginning of the time series. After a month, the temporal evolution of the coefficients is stable for the channel $23.8 \mathrm{GHz}$. For the $37 \mathrm{GHz}$, more time is required to achieve a statistically representative database as the fitting coefficients stabilized only after three months. At the end of the time series, a trend can be observed for both channels. This trend is explained by a seasonal evolution different for measurements and simulations, as seen on the temporal evolution of each data set (not shown here).

As the $23.8 \mathrm{GHz}$ channel has the most important weight in the retrieval of the wet tropospheric correction, we will select the time range for determination of the adjustment according to this channel. This period of time is highlighted by the grey patch on
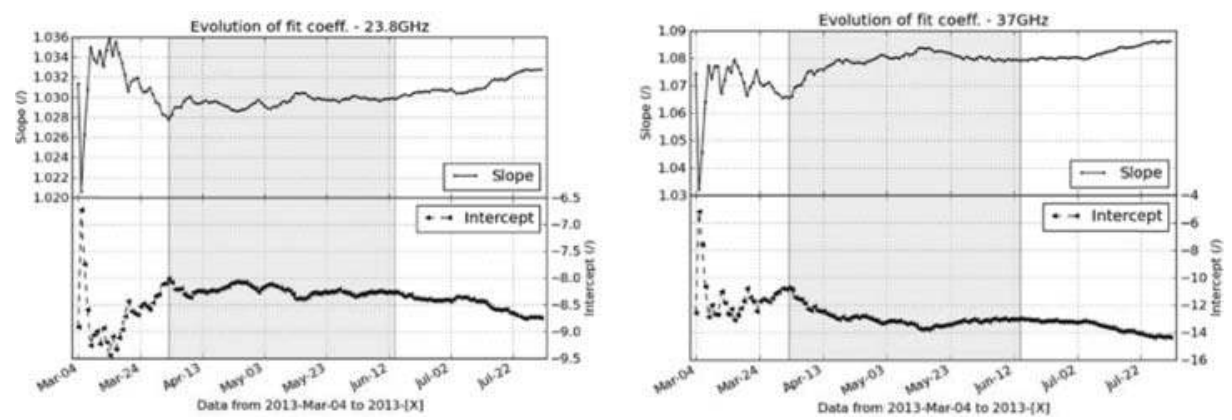

Figure 4. Monitoring of fit slope and intercept of the measured-to-simulated-TB transfer function. 
Figure 4. An average of the slope and intercept values over this time span is performed to compute the values given in Table 3 . These values are currently used in input of the inversion algorithm for the generation of O/IGDR and GDR data "patch 2" version for SARAL/AltiKa.

\subsubsection{Discussion on the comparison between measured and simulated altimeter back-} scattering coefficient in Ka-band. A part of the inversion process, from the incoming signal at the satellite altitude to the column integrated atmospheric parameters, consists in the deconvolution of the surface contribution from the atmospheric one. As the brightness temperature emitted by a given target is defined by the product of its emissivity and its temperature, information on both surface temperature and roughness is needed. On three channels radiometer, as AMR on Jason-2, the surface characterization is provided by the $18.7 \mathrm{GHz}$ channel which is sensitive to surface temperature, surface roughness and atmospheric water vapor, bringing valuable additional information to the retrieval process. In case of a two channels radiometer, roughness information only is provided by the altimeter backscattering altimeter.

As for the brightness temperatures, the learning database is set with a simulated $\sigma_{0}$ : the ocean surface roughness for a non-fully developed sea state is simulated using the ECMWF wind as an input to the sea surface spectrum developed by Elfouhaily et al. (1987) and a two-scaled decomposition of the surface. A two-way atmospheric attenuation at the altimeter central frequency is then computed and added to the simulated $\sigma_{0}$ using the same radiative transfer model used for the brightness temperatures: it is thus directly comparable to $\sigma_{0}$ estimated by the retracking of the waveform.

Multiple comparisons performed between simulations and altimeter measurements at $\mathrm{Ku}, \mathrm{C}$, and $\mathrm{S}$ bands (Lemaire 1998) proved the validity of this approach. This approach has been developed under certain assumptions and limitations exist, mainly related to the sea surface spectrum.

Comparing simulations to measurements, the first limitation is that the sea surface characterized by Elfouhaily spectrum only depends on wind (an empirical relation is used to compute wave height). The consequences are two-fold: errors on the input wind will lead to errors on $\sigma_{0}$ and the results will not be optimal for nonwind-driven waves. The sea surface description will also not be optimal for very low roughness (below $1 \mathrm{~cm}$ ), leading to larger errors for small wind speed/flat surface conditions (below $1 \mathrm{~m} / \mathrm{s}$ ) and for large observation central frequency, more sensitive to small scales (larger than $30 \mathrm{GHz}$ ). Indeed, the comparison between the simulations and TOPEX altimeter measurements performed by Lemaire shows a larger dispersion for low wind conditions (below $3 \mathrm{~m} / \mathrm{s}$ ) and a larger dispersion at $\mathrm{Ku}$ band than at $\mathrm{C}$ band as well.

Table 3

Coefficients of the measured-to-simulated-TB transfer function applied on AltiKa "patch 2" product version

\begin{tabular}{lcc}
\hline & Coefficients used for the adjustment of inversion algorithm (Patch 2) \\
\hline & $23.8 \mathrm{GHz}$ & $37 \mathrm{GHz}$ \\
\hline Slope & 1.0295 & 1.0789 \\
Intercept & -8.234 & -12.953 \\
\hline
\end{tabular}


Then, the correlation between the simulated and the measured $\sigma_{0}$ is small compared to the correlation obtained for TB (respectively about 0.80 and larger than 0.95 , see Figure 5) and, considering the usual small weight of Ku-band $\sigma_{0}$ on the retrieval process, still compared to TB, only a bias is usually adjusted to ensure the consistency between the simulation and the measurements within the "mixedl" approach.

Now the correlation between measurements and simulations is slightly larger at Ka-band (0.83) than at Ku-band (0.77) using the same filtering than defined for the brightness temperatures comparison. But comparing measurements and simulations without filtering or collocation criteria, the limitation of the simulation of $\sigma_{0}$ at Kaband appears. Figure 6 shows the percentile computed for the simulations (solid lines) and the measurements (dashed lines) at Ka-band (AL-MWR measurements, bold lines) and $\mathrm{Ku}$-band (Jason-2 measurements, thin lines). A bias is added to the measurements in order to align the statistics. The difference between simulations and measurements is larger at Ka-band for large values of $\sigma_{0}$ (the last $10 \%$ of the data). As seen on the focus on the central part of the distribution (Figure 6, top right), measurements and simulations are close for $70 \%$ of Ku-band data (difference lower than $0.2 \mathrm{~dB}$ ) and when the difference is lower than $0.1 \mathrm{~dB}$ for $55 \%$ of Ka-band data. The backscattering coefficient being lower at Ka-band than at Ku-band, the impact is larger at Ka-band. Moreover, as seen in the histograms (Figure 6, bottom), the differences are larger in the central part of the distributions, both at Ku- and Ka-band.

Further investigations are needed to assess the source of these differences. As said at the beginning of this section, limitations are known for the simulations but the statistics of $\sigma_{0}$ estimated from the waveforms are impacted by the cloud liquid water content and rain events, with a larger impact at Ka-band than at Ku-band but potentially by surface effects as well (small scale roughness, Gaussianity assumption of the waves).

Finally, with no a priori on the impact of the Ka-band $\sigma_{0}$ on the retrieval performances, a bias of $+0.5 \mathrm{~dB}$ is added to the measurements in order to increase the consistency between measurements and simulations.
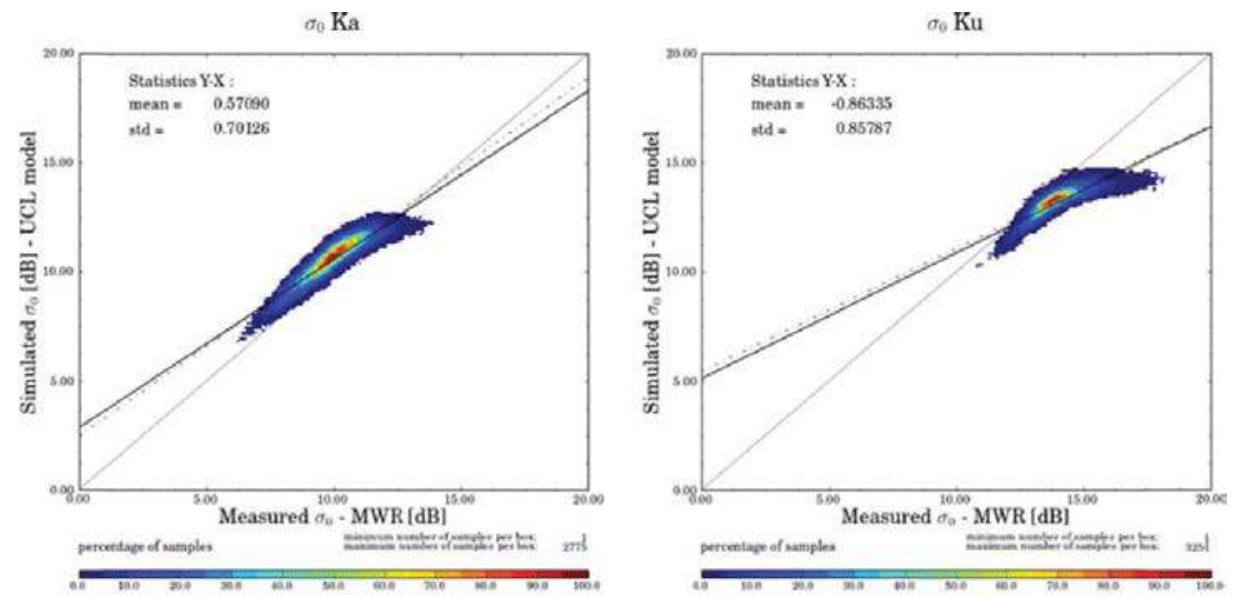

Figure 5. Scatterplots between simulated $\sigma_{0}$ and measurements at $35.75 \mathrm{GHz}$ (left) and $13.5 \mathrm{GHz}$ (right). The thin line is the bisecting line; the bold and the dashed lines respectively refer to a nonweighted linear regression and a weighted linear regression (taking into account the density in each bin). 

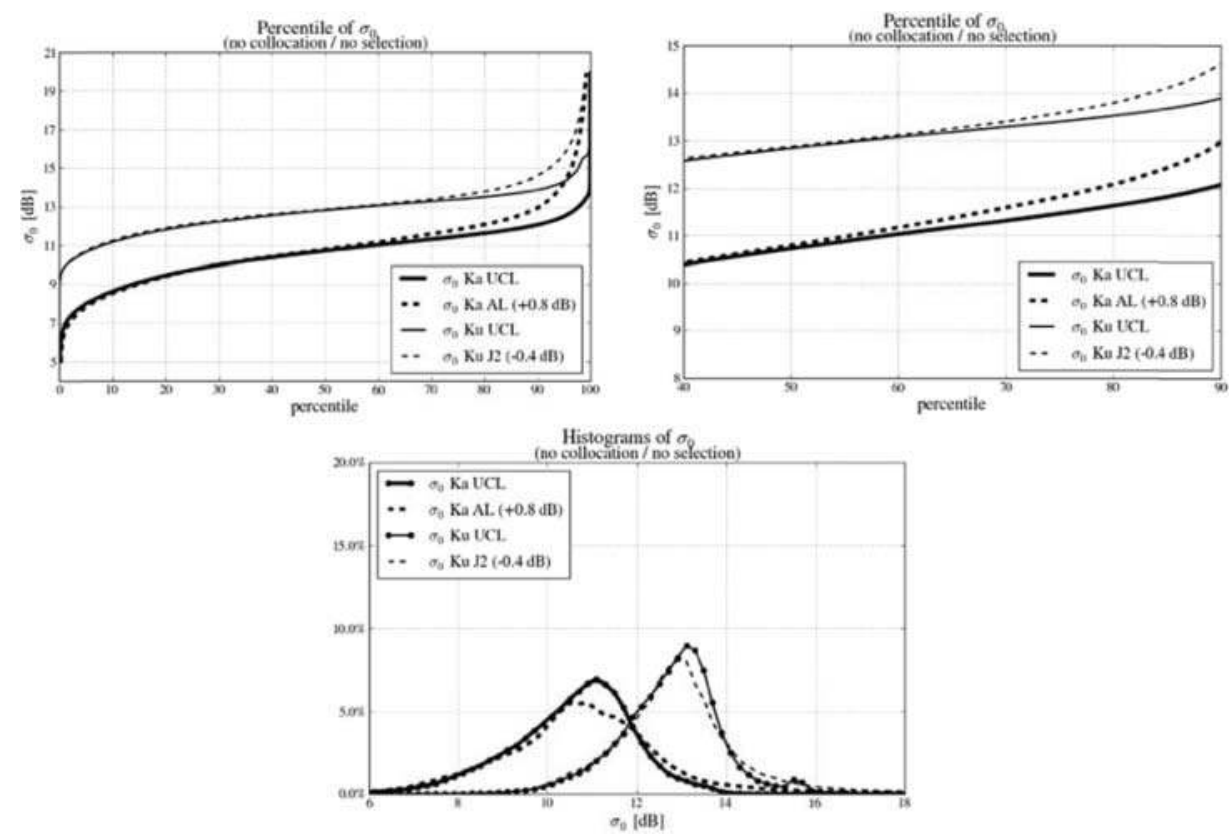

Figure 6. Percentiles (top) and histogram (bottom) of $\sigma_{0}$ : Ka-band (bold lines) and Ku-band (thin lines), simulated (solid lines) and measured (dashed lines).

3.1.4. First validation results on the wet tropospheric correction. Figure 7 shows the histogram of the difference between the radiometer ("mixed" approach) and ECMWF wet tropospheric correction, referred as D_TROPO (radiometer-ECMWF). The impact of the transfer function between simulations and measurements is clearly seen with a reduction of the bias (from $+0.92 \mathrm{~cm}$ to $-0.60 \mathrm{~cm}$ ) and a slight reduction of the standard deviation (from $1.71 \mathrm{~cm}$ to $1.65 \mathrm{~cm}$ ). This latter is still larger for "patch 2" version of the WTC (including the transfer function) than for Jason-2 $(1.29 \mathrm{~cm})$. Analyzing the maps of

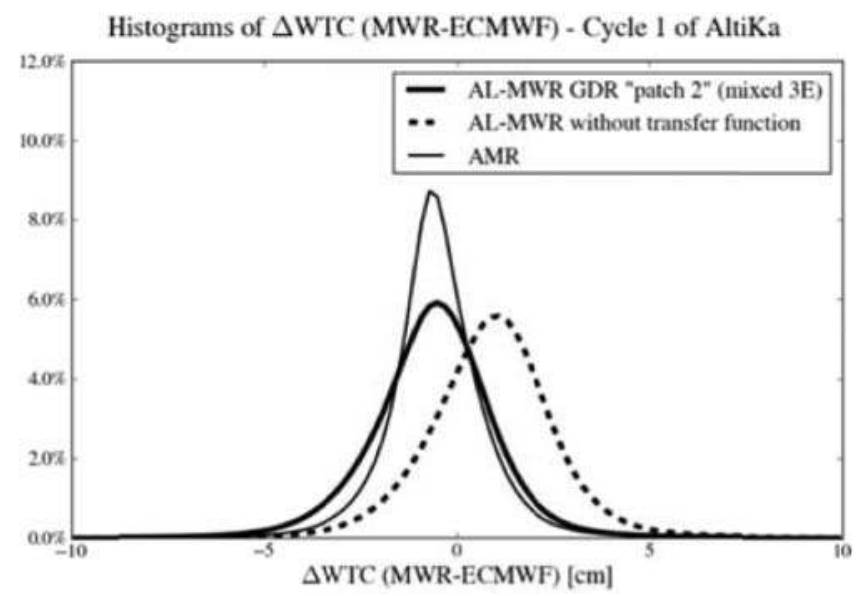

Figure 7. Histogram of WTC differences between radiometer (AL-MWR "patch 2" product version and Jason-2/AMR) and ECMWF. 
D_TROPO for the two radiometers (not shown here), the "patch 2" version of the WTC for AL-MWR is indeed too dry on the Intertropical Convergence Zone (ITCZ) region and too wet at high latitudes, compared to ECMWF WTC (and to Jason-2 WTC by double difference).

The comparison to ECMWF WTC is only a first step in the validation of the "mixed" approach WTC but the performance seems not optimal. In order to assess the source of this degradation, an alternative retrieval approach is proposed, based on the measurements rather than the simulations.

\subsection{The Empirical Approach}

With the empirical approach, the inversion process is directly established from the measurements. The learning database is built from the two TB and the backscattering coefficient, respectively, measured by the radiometer and the altimeter on one hand and the ECMWF WTC on the other hand, interpolated on AltiKa ground track both in time and space, linearly from the two closest analyses (six hours apart) and bi-linearly from the four closest profiles. The first 10 cycles of SARAL/AltiKa is used and 1 point over 7 is selected for latitudes between $\pm 60^{\circ}$. The same method as with the "mixed" approach is applied to build the learning database and the test database and the same neural network architecture is used for the inversion process.

Compared with the "mixed" approach, the empirical approach is less efficient by construction. First, no a priori knowledge on the physics of the surface and the atmospheric properties is needed and this could be a limitation for potential improvements. Then, the consistency between the measurements and the atmospheric and surface conditions is clearly lower than with the "mixed" approach, due to the interpolation of the model onto AltiKa ground track. The comparison between the two methods will provide useful information on what are the unexpected issues with the "mixed" approach.

\section{Evaluation of the Performances of SARAL/AltiKa Wet Tropospheric Correction}

\subsection{Evaluation Criteria}

Different diagnostics are usually combined to evaluate the performances of a new wet tropospheric correction: comparison to the correction provided by other instruments (Thao et al. 2015), comparison to a modeled correction (Obligis et al. 2009), and comparison to radiosondes (Obligis et al. 2006). Then, a critical part of the discussion focuses on the errors on the new correction and on the reference.

The performances of different wet tropospheric correction retrievals are here quantified against the variance of sea surface height (SSH) differences at crossovers. The main advantage of the variance of SSH criteria is that this method does not require any external reference. This metric is commonly used to estimate the overall altimeter system performance and a detailed comparison between WTC estimated from atmospheric analyses and radiometers can be found in Legeais et al. (2014).

Assuming the SSH variability is almost null within a period of 10 days, the best correction, included in the SSH computation (e.g., atmospheric, ionospheric, tide gauges), will provide the smallest variance of the SSH differences at crossovers, computed between ascending and descending passes. 
In order to quantify the benefit from radiometer WTC, a SSH is computed using the ECMWF WTC (SSH_ECMWF) and another one with the radiometer WTC (SSH_RAD). The variance of SSH differences at crossovers is computed for both SSH (VAR(SSH_ECMWF) and VAR(SSH_RAD)). Finally, the difference between the two variances is computed, referred as $\triangle \mathrm{VAR}=\mathrm{VAR}\left(\mathrm{SSH} \_\mathrm{RAD}\right)$ - VAR (SSH_ECMWF).

Compared with the model, the radiometer better solves the small spatial and temporal scales so SSH_RAD is expected to have a smaller variance than SSH_ECMWF (see Legeais et al. 2014). Consequently, $\Delta$ VAR is negative at a global scale, which is the signature of an improvement of the altimetry system. Moreover, the radiometer WTC is particularly valuable where the quantity of water vapor is large and its temporal and variability is high, so the improvements will be particularly significant in the ITCZ and less significant at high latitudes. On the contrary, a degradation is observed whenever $\triangle \mathrm{VAR}$ is positive. So in the following, "improvement of the performances" (respectively "degradation"”) will be used as shortcut for "improvements of the altimetry system performances using the radiometer WTC instead of ECMWF WTC" (respectively "degradation").

For the first time in the context of the evaluation of different WTC retrieval algorithms, we combine three diagnostics related to the variance of SSH differences at crossovers. The global performances are quantified by the average over the temporal evolution of $\Delta$ VAR. Gridded maps $\left(1^{\circ} \times 1^{\circ}\right)$ of the averaged $\Delta$ VAR over the whole period of study give useful information on the spatial distribution of the performances. Finally, the zonal variation of $\triangle \mathrm{VAR}$ computed from the averaging of the gridded map along each band of latitudes allows a finer analysis of the results.

\subsection{Description of the Dataset and of the Retrieval Algorithms}

The different algorithms evaluated hereafter are named after the method used to set the NN coefficients ("mixed" or "empirical") and after the inputs used for the retrieval as summed up in Table 4.

The performances of AL-MWR are compared to AMR on Jason-2 over the first 10 cycles of AltiKa, from March 2013 to March 2014. A detailed description of the method used for the official retrieval for AMR can be found in Brown et al. (2004): it takes benefit from the three channels of the AMR, the $23.8 \mathrm{GHz}$ channel, a CLWC channel at $34 \mathrm{GHz}$, and a $18.7 \mathrm{GHz}$ channel well correlated to both water vapor and surface properties (mainly roughness and SST).

Table 4

Description of the inputs for the different retrievals short names

\begin{tabular}{ll}
\hline Name & \multicolumn{1}{c}{ Input(s) } \\
\hline $1 \mathrm{E}$ & $23.8 \mathrm{GHz} \mathrm{TB}$ \\
$2 \mathrm{E}$ & $23.8 \mathrm{GHz} \mathrm{TB}+\mathrm{CLWC} \mathrm{TB}$ \\
$3 \mathrm{E}$ & $23.8 \mathrm{GHz} \mathrm{TB}+\mathrm{CLWC} \mathrm{TB}+\sigma_{0}$ \\
$4 \mathrm{E}$ & $23.8 \mathrm{GHz} \mathrm{TB}+\mathrm{CLWC} \mathrm{TB}+\sigma_{0}+\mathrm{SST}$ \\
\hline
\end{tabular}


For the present comparison and in order to ensure its consistency, the same methods, "mixed" (based on 2012 ECMWF analyses and simulation) and "empirical" (based on 2013/2014 measurements) with different inputs, have been applied to both instruments.

\subsection{Results}

Figure 8 shows the performance of the "patch 2" version of AltiKa product, the classical "mixed" approach using the classical three inputs: $23.8 \mathrm{GHz}$ and CLWC channel brightness temperature plus the altimeter backscattering coefficient, referred here as "mixed$3 \mathrm{E}$ " algorithm. On the left, an improvement of the altimetry system is observed on equatorial and tropical regions, but a degradation clearly occurs on regions of high latitudes larger the $40^{\circ} \mathrm{N}$ and $40^{\circ} \mathrm{S}$. This is also illustrated by the variation of $\Delta \mathrm{VAR}$ with the latitude (see Figure 8, right): the performances of AL-MWR are similar to AMR between $40^{\circ} \mathrm{N}$ and $40^{\circ} \mathrm{S}$ and clearly degraded outside this area.

In order to find an explanation for the degradation of the classical approach for ALMWR, we analyze the improvement of the performances when using more and more inputs for the retrieval. Figure 9 shows the variation of $\triangle$ VAR against the latitudes of four different algorithms applied on AL-MWR (top left) and AMR (top right).

As expected, the performances improve with the number of inputs for both instruments. The best ones are obtained with four inputs, adding the SST to the three classical inputs, confirming the results shown in Obligis et al. (2009) (see Table 5). In this latter case, $\triangle \mathrm{VAR}$ is close for AL-MWR and AMR at a global scale but a degradation is still observed at high latitudes for AL-MWR (Figure 9, top left).

Another way to analyze the improvement of the performances with the number of inputs is to compute the gain on $\triangle \mathrm{VAR}$ when adding the inputs one by one. For instance, $\Delta \mathrm{VAR}$ is equal to $+3.8 \mathrm{~cm}^{2}$ with the algorithm $1 \mathrm{E}\left(23.8 \mathrm{GHz} \mathrm{TB}\right.$ only) and $-0.5 \mathrm{~cm}^{2}$ with the algorithm $2 \mathrm{E}$ (TB from both channels) for AL-MWR. Then, the gain on $\triangle \mathrm{VAR}$ brought by the CLWC channel is equal to $+4.3 \mathrm{~cm}^{2}$; similarly the gain on $\Delta$ VAR brought by the CLWC channel for Jason- 2 being equal to $+4.6 \mathrm{~cm}^{2}$ and one can conclude that the quantity of information brought by the CLWC channel is almost the same for both instruments.

Adding the altimeter backscatter coefficient actually slightly improves the performances for AL-MWR and AMR, respectively, of $+0.3 \mathrm{~cm}^{2}$ and $+0.1 \mathrm{~cm}^{2}$. As expected at a global scale, the amount of information given by $\sigma_{0}$ is small and with a larger impact at high latitudes (Figure 9, top left and right) where the integrated water vapor is small and
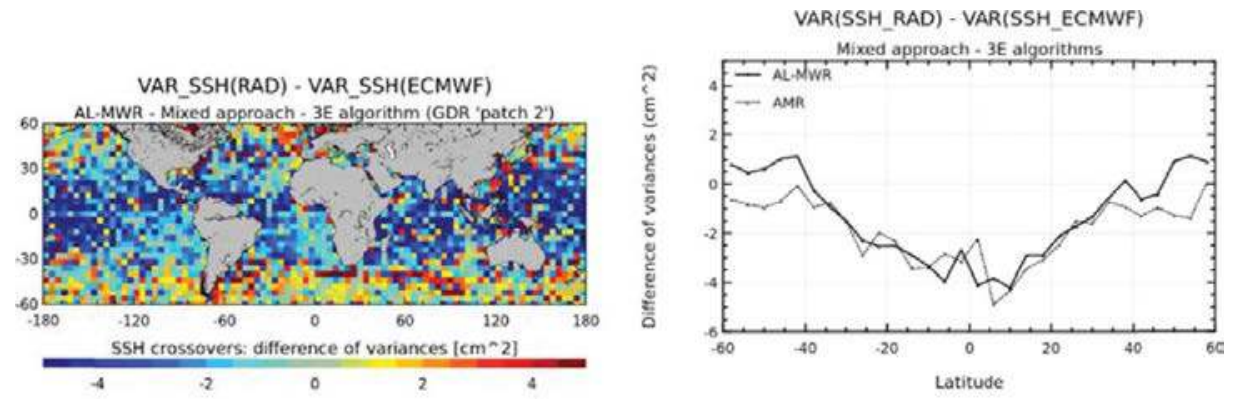

Figure 8. Performances of the "mixed - 3E" algorithm for AL-MWR: a gridded $1^{\circ} \times 1^{\circ}$ map (left) and the variation against latitudes for AL-MWR and AMR (right). 

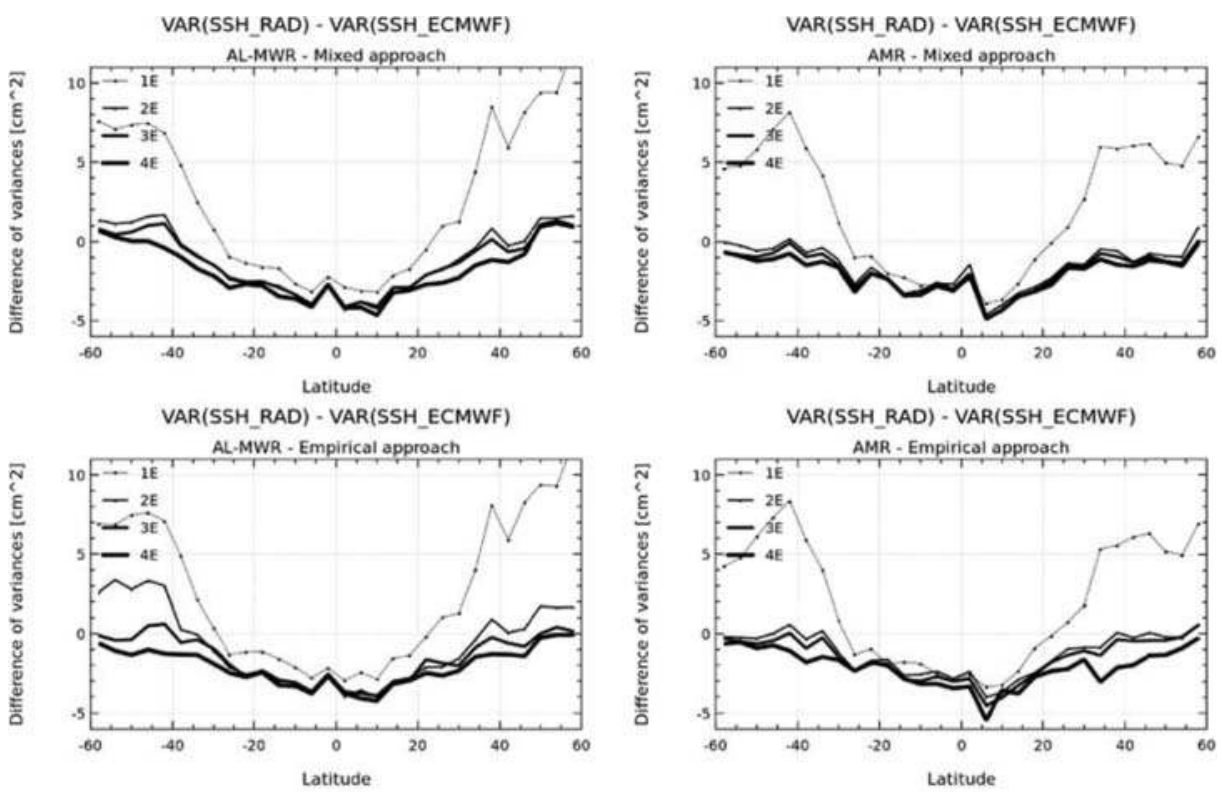

Figure 9. Variation of $\triangle V A R$ against latitudes: results for AL-MWR (left) and AMR (right) for the "mixed" approach (top) and the "empirical" approach (bottom) for 1E, 2E, 3E, and 4E algorithms.

the wind speed is large: $\sigma_{0}$ is valuable where the weight of the surface roughness on the TB measured by the radiometer is larger.

Finally, the gain on $\triangle$ VAR brought by the SST is larger for AL-MWR $\left(+0.5 \mathrm{~cm}^{2}\right)$ than for AMR $\left(+0.2 \mathrm{~cm}^{2}\right)$. The SST seems to compensate for the poor performances using the classical inputs for AL-MWR. It clearly reduces the bump between the latitude $20^{\circ}$ and $40^{\circ}$ (north and south, see Figure 9, top left) but it is not sufficient to avoid the increase of $\triangle \mathrm{VAR}$ with the latitude increasing.

The analyses of the same metrics applied to the "empirical" approach will allow us to confirm the issues on how the Ka backscattering coefficient is handled with the "mixed" approach.

Figure 10 shows the performance of the "empirical" approach with four inputs, the so-called "empirical-4E" algorithm, using $23.8 \mathrm{GHz}$ and CLWC channel TB, the altimeter backscattering coefficient and the SST. On the top left is shown $\triangle$ VAR gridded on a $1^{\circ} \times 1^{\circ}$ map for AL-MWR. The improvement is now clearly global, with still an expected

Table 5

Global performances for AL-MWR and AMR using the "mixed" approach

\begin{tabular}{lcc}
\hline & \multicolumn{2}{c}{ Performances of the mixed approach $\left[\mathrm{cm}^{2}\right]$} \\
\cline { 2 - 3 } Retrieval algorithm & AL-MWR & AMR \\
\hline 1E & +3.8 & +3.4 \\
$2 \mathrm{E}$ & -0.5 & -1.2 \\
3E & -0.8 & -1.3 \\
4E & -1.3 & -1.5 \\
\hline
\end{tabular}




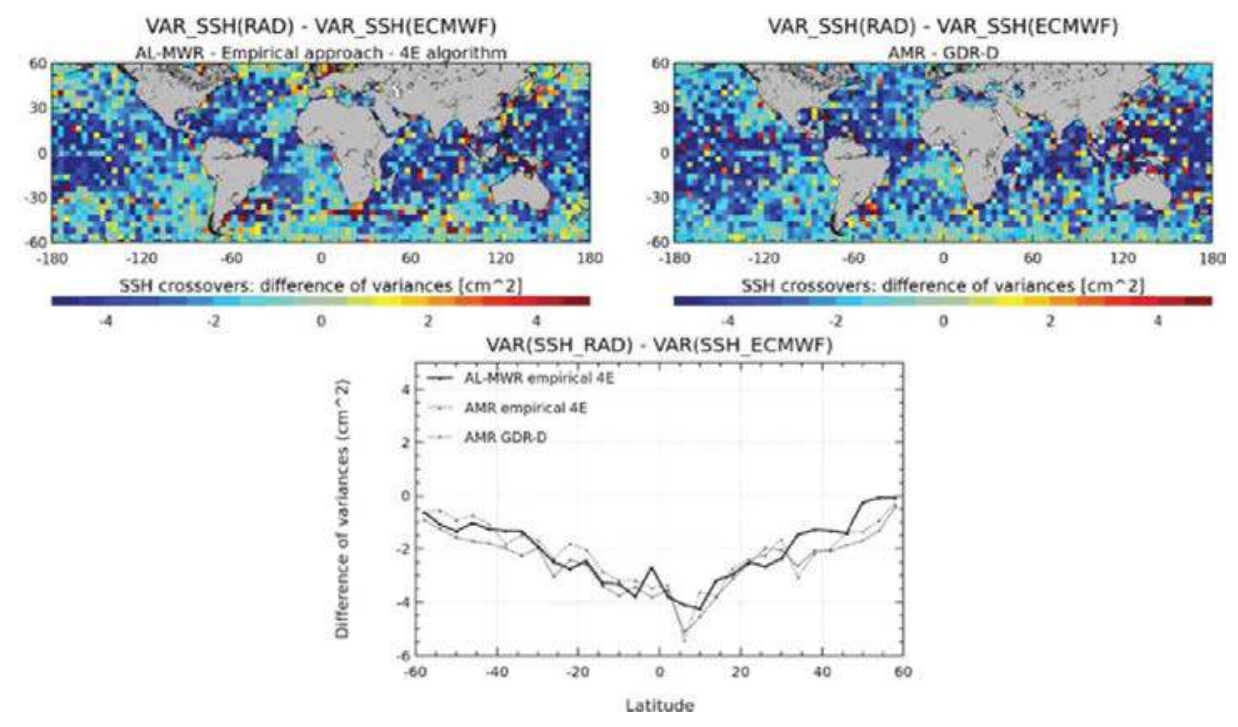

Figure 10. Performances of the "empirical 4E" algorithm applied to AL-MWR and comparison to AMR GDR-D: top, gridded $1^{\circ} \times 1^{\circ}$ maps, bottom, the variation against latitudes.

zonal signature, the improvement being larger on equatorial and tropical regions than at high latitudes (see Figure 10, bottom). The results for AltiKa and Jason-2 are similar at a global scale, the improvement being equal to $-1.8 \mathrm{~cm}^{2}$ for AL-MWR.

The performances of $1 \mathrm{E}$ algorithms $(23.8 \mathrm{GHz} \mathrm{TB}$ only) with the "empirical" approaches are similar for the two instruments and the variations against the latitude are close to the "mixed" approach (Figure 9, bottom). The gain on $\triangle$ VAR brought by the CLWC channel is larger for AMR than for AL-MWR $\left(+4.2 \mathrm{~cm}^{2}\right.$ against $\left.+3.6 \mathrm{~cm}^{2}\right)$ and the performance is slightly poorer at high south latitudes for AL-MWR with the "empirical" method than with the "mixed" approach. Nevertheless, the difference between AL-MWR and AMR for the 2E algorithm is the same for the "empirical" approach and for the "mixed" approach $\left(+0.7 \mathrm{~cm}^{2}\right)$. It's also worth noting that, in this configuration, the "mixed" approach offers better performances than the "empirical" approach for both instruments: the impact on $\triangle \mathrm{VAR}$ is equal to $+0.4 \mathrm{~cm}^{2}$ and is explained by the nonconsistency between the measurements and the model during the learning of the empirical approach.

Much larger differences are observed for the gain on $\Delta$ VAR brought by $\sigma_{0}$. The global performances for AL-MWR and AMR are close with the "empirical" approach using the classical three inputs ( $3 \mathrm{E}$ algorithms), respectively $-1.2 \mathrm{~cm}^{2}$ and $-1.0 \mathrm{~cm}^{2}$ (Table 6), but this results from a different handling of $\sigma_{0}$ by the retrievals.

The difference between the two instruments on the gain on $\Delta$ VAR brought by $\sigma_{0}$ with the "empirical" approach is equal to $+1 \mathrm{~cm}^{2}$ : the gain on $\triangle \mathrm{VAR}$ is equal $+1.3 \mathrm{~cm}^{2}$ for AL-MWR and $+0.3 \mathrm{~cm}^{2}$ for AMR. Part of this gain compensates for the poor performances of AL-MWR compared with AMR and the "empirical" approach at high latitudes (Figure 9, bottom), but a positive effect is clearly seen on high latitudes for AL-MWR, especially above $40^{\circ} \mathrm{N}$ where the performances are now better with the "empirical" approach than with the "mixed" approach. This may also be the signature of a larger quantity of surface information brought by the AltiKa Ka-band backscattering coefficient than with the one of Jason-2 at Ku-band. Nevertheless, at this level of investigation, 
Table 6

Global performances for AL-MWR and AMR using the "empirical" approach

\begin{tabular}{lcc}
\hline & \multicolumn{2}{c}{ Performances of the empirical approach $\left[\mathrm{cm}^{2}\right]$} \\
\cline { 2 - 3 } Retrieval algorithm & AL-MWR & AMR \\
\hline $1 \mathrm{E}$ & +3.7 & +3.4 \\
$2 \mathrm{E}$ & +0.1 & -0.8 \\
$3 \mathrm{E}$ & -1.2 & -1.0 \\
$4 \mathrm{E}$ & -1.8 & -1.6 \\
\hline
\end{tabular}

nothing allows to separate between a property of the Ka-band itself, compared to the $\mathrm{Ku}$-band, or the intrinsic characteristics of the altimeters, their respective spatial resolutions for instance.

Then the difference is also large between the gain on $\triangle \mathrm{VAR}$ brought by $\sigma_{0}$ with the "empirical" and with the "mixed" approach for AL-MWR. Indeed, the performances are better with the "empirical" approach than with "mixed" approach in this configuration (Tables 5 and 6) for AL-MWR $\left(-0.4 \mathrm{~cm}^{2}\right)$ when, as expected, the performances are degraded for AMR $\left(+0.3 \mathrm{~cm}^{2}\right)$ using the "empirical" approach instead of the "mixed", with the same impact than in $2 \mathrm{E}$ configuration.

Summarizing, with a Ku-band $\sigma_{0}$, the performances are better with the "mixed" approach than with the "empirical" approach (respectively $-1.3 \mathrm{~cm}^{2}$ and $-1.0 \mathrm{~cm}^{2}$ ) and the gain on $\triangle \mathrm{VAR}$ brought by $\sigma_{0}$ (w.r.t. $2 \mathrm{E}$ algorithm) is close for both methods, respectively, $0.1 \mathrm{~cm}^{2}$ and $0.3 \mathrm{~cm}^{2}$. With a Ka-band $\sigma_{0}$, the performances are better with the "empirical" approach than with the "mixed" approach (respectively $-1.2 \mathrm{~cm}^{2}$ and $-0.8 \mathrm{~cm}^{2}$ ) and the gain on $\Delta$ VAR brought by $\sigma_{0}$ (w.r.t. $2 \mathrm{E}$ algorithm) is much larger with the empirical "approach" $\left(1 \mathrm{~cm}^{2}\right)$ than with the "mixed" approach $\left(0.3 \mathrm{~cm}^{2}\right)$. That is to say, there is a certain amount of surface information in the Ka-band $\sigma_{0}$ (maximum of $1 \mathrm{~cm}^{2}$ ) which is not fully exploited by the "mixed" approach: this is should be related to the inconsistency between the measured $\sigma_{0}$ and the simulated ones, as seen in the previous section, and the difficulty to find a valid transfer function between simulations and measurements. Finally, the gain on $\triangle$ VAR brought by the SST is similar for the two instruments with the "empirical" approach, about $+0.5 \mathrm{~cm}^{2}$.

As shown in Figure 10 (top left), the "empirical" approach with four inputs ("empirical - 4E" algorithm) offers the best performances for AL-MWR. As a reference, $\Delta$ VAR map for the official (GDR-D version) AMR WTC product (using the JPL retrieval algorithm) is shown on Figure 10 as well (top right) and its zonal variation is plotted on bottom. The global geographical pattern and the zonal variation are similar but AMR GDR-D WTC offers clearly better performances on high oceanic variability regions, as over Agulhas current or over the Gulf Stream, at high latitudes.

Figure 11 allows comparing AL-MWR "empirical - 4E" to Envisat RA2-MWR and AMR. The performance of this latter is computed for two periods, one covering the first ten cycles of AltiKa and the second covering ten cycles of Envisat between April 2011 and end of March 2012. In both cases, the performances of AMR are evaluated with the official GDR-D WTC. The algorithm for RA2-MWR is a classical "mixed" approach (set with ECMWF 2012 analyses and simulations) with the classical three inputs.

On the left panel of Figure 11, $\Delta$ VAR is evaluated at a global scale (at latitudes lower than $60^{\circ}$ ). AMR offers the best performances: the differences compared with AL-MWR 

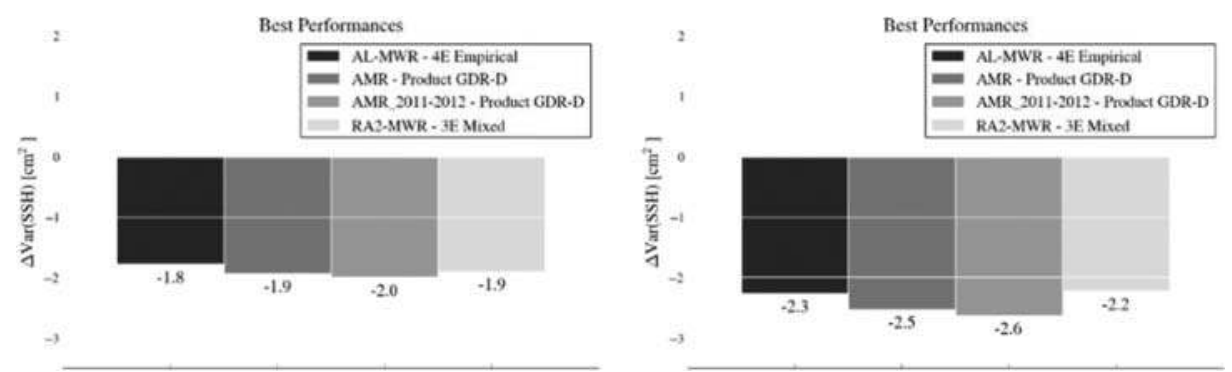

Figure 11. Best performances for AL-MWR, AMR and Envisat at global scale (left) and for low oceanic variability selection (right).

and RA2-MWR are the same and equal to $+0.1 \mathrm{~cm}^{2}$. The same metrics are computed on the right panel of Figure 11 over ocean with low variability (and latitudes between $50^{\circ} \mathrm{S}$ and $50^{\circ} \mathrm{N}$ ): AMR offers the best performances as well and the differences are slightly larger, $+0.2 \mathrm{~cm}^{2}$ compared with AltiKa and $+0.4 \mathrm{~cm}^{2}$ for Envisat.

Finally, Figure 12 shows some metrics for AL-MWR "empirical - 4E" WTC. On top is illustrated the map of the difference between AL-MWR WTC and ECMWF WTC, centered on its mean. As seen on the zonal variation as well (Figure 12, bottom left), the difference between ECMWF WTC and AL-MWR "empirical - 4E" WTC are smaller than between ECMWF WTC and AMR WTC. This is expected since the neural network is trained to be as close as possible to the model: due to the methodology, some dynamic is missing on AL-MWR "empirical - 4E" WTC. As seen on the histogram for the same difference between radiometer and model (Figure 12, bottom right), AL-MWR is more wet compared to AMR WTC, the bias

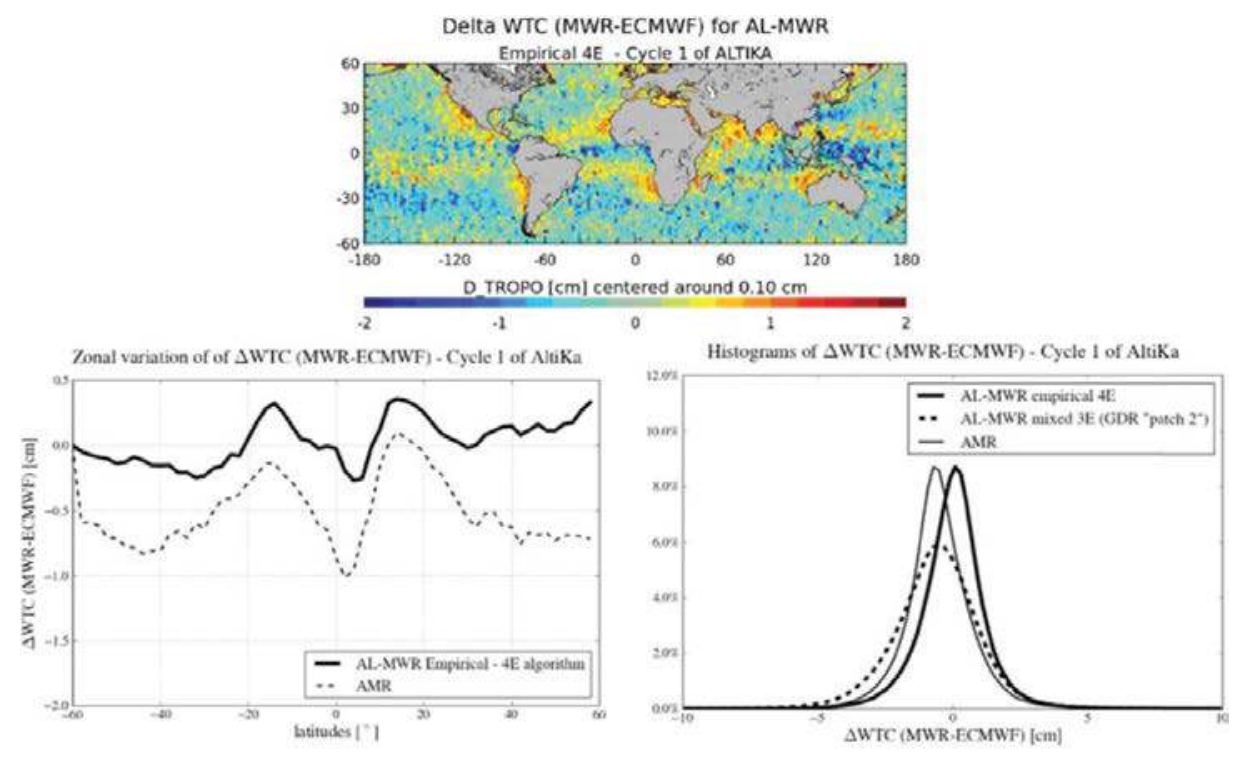

Figure 12. Maps of WTC differences between AL-MWR "empirical - 4E" and ECMWF (top), zonal variation (bottom left) and histogram (bottom right) and comparison to AMR GDR-D. 
being close to $5 \mathrm{~mm}$ and the standard deviation of the difference with ECMWF WTC are equal to $1.29 \mathrm{~cm}$ for both instruments.

As noted by Obligis (2009), the systematic overestimation in the eastern part of the subtropical basins (California and Peru coasts in Pacific, Mauritania, and Namibia coasts in Atlantic) is due to the specific atmospheric stratification in these regions and could be corrected for by adding a new input parameter to the retrieval: the global mean temperature slope value of the profile. Further improvements for AL-MWR are then expected using a five inputs "empirical" approach.

\section{Conclusion}

The in-flight calibration of AltiKa microwave radiometer (AL-MWR) is assessed through the comparison to simulated brightness temperatures and to the comparison to Jason-2 AMR and Metop02 AMSU-A radiometers over geophysical targets, coldest brightness temperatures (TB) over ocean, and hottest TB over the Amazon forest. In each case, the biases between AL-MWR TB and the considered reference are inside reasonable limits, except for a $5 \mathrm{~K}$ bias observed during the comparison between AL-MWR and AMR of coldest TB at $23.8 \mathrm{GHz}$, the differences being attributed to different calibration strategies.

The performances of different configurations for two retrieval strategies of the WTC are systematically evaluated for the first time against the variance of SSH differences at crossovers. The classical "mixed" approach successfully applied to Envisat MWR is compared with a pure empirical method.

The poor performances of the "mixed" approach are attributed to the inconsistency between the simulated and the measured $\sigma_{0}$ and the larger weight of $\sigma_{0}$ on the retrieval performances at Ka-band than at Ku-band.

The performances of the empirical approach using both radiometers TB, the altimeter $\sigma_{0}$ and the sea surface temperature as inputs to the retrieval are close to what was expected with the "mixed" approach and close to the performances of AMR three channels radiometer. Further improvements are expected introducing an additional input parameter related to the specific atmospheric stratification in the eastern part of subtropical basins.

Improvements in the simulation of the backscattering coefficient should be proposed in order to decrease these differences. Updates of the Elfouhaily sea surface spectrum should be studied, including wave heights and wind, as inputs and investigating the signal/surface interaction at scales shorter than $1 \mathrm{~cm}$. Further investigations should be performed on the impact of rain on the altimeter $\sigma_{0}$ as well, in order to determine if a part of the observed differences between simulations and measurements could be attributed to rain events. In this latter case, the implementation of Mie theory (scattering and extinction parameters of a spherical particle) applied to raindrops in the radiative transfer model should be considered (Smith et al. 2002).

\section{Acknowledgements}

This activity is supported by CNES in the framework of the SALP contract for all altimeter missions. The two anonymous reviewers are thanked for their in-depth comments on the manuscript. 


\section{References}

Boukabara, S. A., L. Eymard, C. Guillou, D. Lemaire, P. Sobieski, and A. Guissard. 2002, August. Development of a modified two-scale electromagnetic model simulating both active and passive microwave measurements: Comparison to data remotely sensed over the ocean. Radio Science 37(4):16-1-11.

Brown, S., C. Ruf, S. Keihm, and A. Kitiyakara. 2004. Jason microwave radiometer performance and on-orbit calibration. Marine Geodesy 27(1-2):199-220.

Brown, S. and C. Ruf. 2005, September. Determination of an Amazon hot reference target for the on-orbit calibration of microwave radiometers. Journal of Atmospheric Ocean Technology 22:1340-1352.

Brown, S. 2013, March. Maintaining the long-term calibration of the Jason-2/OSTM advanced microwave radiometer through intersatellite calibration. IEEE Transactions Geoscience Remote Sensing 51(3):1531-1543.

Elfouhaily, T., B. Chapron, K. Katsaros, and D. Vandemark. 1997. A unified wave spectrum for long and short wind-driven waves. Journal of Geophysical Research 102:15781-15796.

Eymard, L., E. Tabary, S. Gérard, S.A. Boukabara, and A. Le Cornec. 1996, March. The microwave radiometer aboard ERS1: Part II-validation of the geophysical products. IEEE Transactions Geoscience Remote Sensing 34(2):291-303.

Eymard, L., E. Obligis, N. Tran, F. Karbou, M. Dedieu, and A. Pilon. 2005. Long-term stability of ERS-2 and TOPEX microwave radiometer in-flight calibration. IEEE Transactions Geoscience Remote Sensing 43:1144-1158.

Guissard, A. and P. Sobieski. 1987. An approximate model for the microwave brightness temperature of the sea. International Journal Remote Sensing 8(11):1607-1627.

Kroodsma, R. A., D. S. McKague, and C. S. Ruf. 2012, June. Inter-calibration of microwave radiometers using the vicarious cold calibration double difference method. IEEE Transactions Geoscience Remote Sensing 5(3):1006-1013.

Legeais, J.-F., M. Ablain, and S. Thao. 2014. Evaluation of wet troposphere path delays from atmospheric reanalyses and radiometers and their impact of the altimeter sea level. Ocean Science 10:893-905.

Lemaire, D. 1998. Non-fully developed sea state characteristics from real aperture radar remote sensing. Doctoral dissertation. l'Université Catholique de Louvain, Belgium.

Obligis, E., L. Eymard, N. Tran, S. Labroue, and P. Femenias. 2006. First three years of the microwave radiometer aboard Envisat: In-flight calibration, processing, and validation of the geophysical products. Journal of Atmospheric Ocean Technology 23:802-814.

Obligis, E., A. Rahmani, L. Eymard, S. Labroue, and E. Bronner. 2009, September. An improved retrieval algorithm for water vapor retrieval: Application to the Envisat microwave radiometer. IEEE Transactions Geoscience Remote Sensing 47(9):3057-3064.

Ruf, C. 2000, January. Detection of calibration drifts in spaceborne microwave radiometers using a vicarious cold reference. IEEE Transactions Geoscience Remote Sensing 38(1):44-52.

Ruf, C. 2002, February. Characterization and correction of a drift in calibration of the TOPEX microwave radiometer. IEEE Transactions Geoscience Remote Sensing 40(2):509-511.

Scharroo, R., J. Lillibridge, and W. Smith. 2004. Cross-calibration and long-term monitoring of the microwave radiometers of ERS, TOPEX, GFO, Jason and ENVISAT. Marine Geodesy 27:279-297.

Steunou, N., N. Picot, P. Sengenes, J. Noubel, M.L. Frery. 2015. AltiKa radiometer: Instrument description and in flight performance. Marine Geodesy 38(S1): this issue.

Smith, A. E., P. Bauer, F. S. Marzano, C. D. Kummerow, D. Mc Kague, A. Mugnai, and G. Panegrossi. 2002, March. Intercomparison of microwave radiative transfer models for precipitating clouds. IEEE Transactions Geoscience Remote Sensing 40(3):541-549.

Thao, S., L. Eymard, E. Obligis, and B. Picard. 2015. Trend and variability of the atmosphere water vapor: A mean sea level issue. Journal of Atmospheric Ocean Technology in press.

Valladeau, G., P. Thibaut, B. Picard, J.-C. Poisson, N. Tran, N. Picot, A. Guillot. 2015. Using SARAL/AltiKa to improve Ka-band altimeter measurements for coastal zones, hydrology and ice: The PEACHI prototype. Marine Geodesy 38(S1): this issue. 